\title{
Toxicity mechanism of sevoflurane in neural stem cells of rats through DNA methylation
}

\author{
$\mathrm{KA} \mathrm{WANG}^{1,2}$, YI TIAN ${ }^{2}$, YINGAI ZHANG ${ }^{3},{\mathrm{XUYING} \mathrm{LI}^{2}, \mathrm{XIAO}^{\mathrm{WEI}}{ }^{2}, \text { HAIYOU HU }^{2} \text { and SHIYUAN XU }}^{1}$ \\ ${ }^{1}$ Department of Anesthesiology, Zhujiang Hospital of Southern Medical University, \\ Guangzhou, Guangdong 510280; Departments of ${ }^{2}$ Anesthesiology and ${ }^{3}$ Central Laboratory, \\ Central South University Xiangya School of Medicine Affiliated Haikou Hospital, Haikou, \\ Hainan 570208, P.R. China
}

Received November 22, 2018; Accepted March 26, 2019

DOI: $10.3892 / \mathrm{etm} .2019 .7553$

\begin{abstract}
The present study investigated the influence of sevoflurane on the cytotoxicity of neural stem cells of rats and deoxyribonucleic acid (DNA) methylation, and analyzed the correlation between degree of methylation and neurotoxicity of sevoflurane. Ten healthy Sprague-Dawley rats aged 6-8 weeks were randomly selected. The neural stem cells in the hippocampus of rats were isolated, followed by multiplication culture and induced differentiation. The nerve-related factors were observed and detected under a microscope. Moreover, the neural stem cells were treated with sevoflurane in different concentrations. Three wells were only added with the normal medium as the control group $\left(\mathrm{C}_{0}\right), 3$ wells were added with the low-concentration sevoflurane $(0.2 \mathrm{~g} / \mathrm{ml})$ prepared by the medium as the low-concentration group $\left(\mathrm{C}_{1}\right), 3$ wells were added with the moderate-concentration of sevoflurane $(0.5 \mathrm{~g} / \mathrm{ml})$ as the moderate-concentration group $\left(\mathrm{C}_{2}\right)$, and 3 wells were added with the high-concentration sevoflurane $(1 \mathrm{~g} / \mathrm{ml})$ as the highconcentration group $\left(\mathrm{C}_{3}\right)$. The apoptosis rate was detected and calculated via Cell Counting Kit-8 (CCK-8) assay, the content of genomic DNA methylation in neural stem cells in each group was detected via high-performance liquid chromatography (HPLC), and the distribution of methylation in the chromosome in each group was compared. During the culture, neurospheres were produced, and the expression levels of four neural markers were increased. With the increase of sevoflurane concentration and the prolongation of time, the apoptosis rate of stem cells was increased. The content of methylation in cells treated with sevoflurane in a higher concentration was higher than that in other groups $(\mathrm{P}<0.05)$. According to the Pearson's correlation analysis, the content of methylation in neural stem cells was directly proportional to the concentration of sevoflurane.
\end{abstract}

Correspondence to: $\mathrm{Dr}$ Shiyuan Xu, Department of Anesthesiology, Zhujiang Hospital of Southern Medical University, 253 Gongye Avenue, Guangzhou, Guangdong 510280, P.R. China E-mail: ben7692@126.com

Key words: sevoflurane, DNA methylation, rat, neural stem cells, cytotoxicity
Methylation mostly occurred in the autosome, and the content of methylation in the high-concentration group was higher than those in the moderate-concentration, low-concentration and control groups $(\mathrm{P}<0.05)$. In conclusion, the concentration of sevoflurane can affect the degree of methylation in neural stem cells of rats and produce certain cytotoxicity.

\section{Introduction}

Nerve cells are non-renewable cells. Due to ageing and damage of external environment, nerve cells are injured, leading to apoptosis. A variety of related diseases are induced when the number of nerve cells gradually declines $(1,2)$, such as Alzheimer's disease, Parkinson's disease, cerebellar atrophy and other neurodegenerative diseases (3). At present, maintenance treatment prevails in the drug therapy for neurodegenerative diseases in clinic, but no radical efficacy is obtained (4). Relatively speaking, neural stem cells have such characteristics as self-amplification and constant updating, as well as the potential of directional differentiation into neuronal cells, which are considered as the biomaterial that is able to cure neurodegenerative diseases (5). However, the premise is that the number of neural stem cells in the body is sufficient and they are not damaged or reduced (6). Anesthetics are currently drugs with the greatest direct impact on the nerves, and are applied most frequently. As a commonly-used anesthetic, sevoflurane used to be considered as a landmark drug in inhalation anesthesia (7), which is characterized by low dose of muscle relaxant and rapid postoperative recovery, and it is often used in anesthesia for children $(8,9)$. However, there have been different reports on the effect of sevoflurane on nerves so far. In the present study, therefore, the effect of sevoflurane on neural stem cells was investigated with neural stem cells and deoxyribonucleic acid (DNA) methylation as entry points.

\section{Materials and methods}

Experimental materials. A total of 10 healthy specific pathogen-free Sprague-Dawley (SD) rats aged 6-8 weeks (Beijing Vital River Laboratory Animal Technology Co., Ltd., Beijing, China) and sevoflurane (Beijing Baitaike Medical Co., Ltd., Beijing, China) were used. The rats were kept in cages 
Table I. Primer sequences.

Gene name

Primer sequences

Nestin

Glial fibrillary acidic portein (GFAP)

$\beta$-tubulin

Microtubule-associated protein-2 (MAP-2)

$\beta$-actin
Forward: 5'-CCTCCACCCTTGCCTGCTACCCT-3' Reverse: 5'-ACGGAGCCTGTTTCCTCCCACC-3'

Forward: 5'-TAGACAGGAAGCATGAAGCCACC3' Reverse: 5'-TGCAAACTTGGAGCGGTACCACTCT-3'

Forward: 5'-TGGGCCAAGGGTCACTACAC-3' Reverse: 5'-CTGATGCGGTCGGGATACTC-3'

Forward: 5'-GCACGGCGGACCACCAGGTC-3' Reverse: 5'-TGGCGACCTTCTTCTCACTC-3'

Forward: 5'-GTGGACATCCGCAAAGAC-3' Reverse: 5'-GAAAGGGTGTAACGCAACTA-3' with controlled temperature and light/dark cycles $\left(24^{\circ} \mathrm{C}\right.$ and 12:12-h light/dark cycles), humidity $(60 \pm 10 \%)$ and free access to food and water.

Main reagents. Neural stem cell culture medium (R\&D Systems, Inc., Minneapolis, MN, USA), Cell Counting Kit-8 (CCK-8; Dojindo China Co., Ltd., Beijing, China), primary and secondary antibodies (Sigma-Aldrich; Merck KGaA, Darmstadt, Germany) and primers (Sangon Biotech Co., Ltd., Shanghai, China).

\section{Methods}

Isolation and culture of neural stem cells (10). The brain tissues were peeled off from Sprague-Dawley rats (male, 200 $\pm 20 \mathrm{~g}$ ) sacrificed in advance on a super clean bench under sterile conditions, the hippocampus was isolated, and the meninges and visible blood vessels were removed. The remaining hippocampal tissues were cut into pieces with sterile scissors and added with $0.25 \%$ trypsin, placed in a water bath at $37^{\circ} \mathrm{C}$ and centrifuged for $5 \mathrm{~min}(800 \mathrm{x} \mathrm{g} / \mathrm{min})$ at $4^{\circ} \mathrm{C}$ after $15 \mathrm{~min}$. After the supernatant was discarded, the mixture was filtered through a 400-mesh filter, added with neural stem cell culture medium, pipetted and mixed evenly, followed by counting. Then cells were inoculated into a $75-\mathrm{cm}^{2}$ culture flask $\left(5 \times 10^{6} / \mathrm{cm}^{2}\right)$ and cultured in an incubator with $\mathrm{CO}_{2}$ at $37^{\circ} \mathrm{C}$. The medium was replaced once every 3 days, observed and recorded.

The present study was approved by the Ethics Committee of Central South University Xiangya School of Medicine Affiliated Haikou Hospital (Haikou, China).

Reverse-transcription-quantitative polymerase chain reaction (RT-qPCR) detection. Ribonucleic acid (RNA) was extracted from neural stem cells using TRIzol, and $1 \mu \mathrm{g}$ RNA was reverse transcribed to obtain complementary DNA (cDNA). The cDNA concentration was adjusted, and the messenger RNA (mRNA) level was detected using the Bio-Rad CFX96 PCR instrument (Bio-Rad Laboratories, Inc., Hercules, CA, USA). The reaction conditions were as follows: $95^{\circ} \mathrm{C}$ for $2 \mathrm{~min}$, $94^{\circ} \mathrm{C}$ for $15 \mathrm{sec}, 50^{\circ} \mathrm{C}$ for $25 \mathrm{sec}$, a total of 40 cycles. The corresponding primer sequences are shown in Table I. The results were analyzed using the $2^{-\Delta \Delta \mathrm{Cq}}$ method (11).
Western blot analysis. Cells were ground in liquid nitrogen, lysed on ice for $30 \mathrm{~min}$ and centrifuged at 3,000 x g for $10 \mathrm{~min}$ to obtain the supernatant. A portion of supernatant was taken, the protein content the protein was extracted with ProteoPrep ${ }^{\circledR}$ protein extraction kit (Sigma St. Louis, MO, USA) and protein content was detected with BCA protein quantitative kit and adjusted to $100 \mu \mathrm{g}$, and the $5 \mathrm{X}$ reduced loading buffer was added and boiled for $10 \mathrm{~min}$. A total of $9 \mu \mathrm{l}$ sample solution was added slowly with a microsyringe into the $10 \%$ polyacrylamide gel loading well, followed by sodium dodecyl sulfate polyacrylamide gel electrophoresis (SDS-PAGE) at $80 \mathrm{~V}$. After electrophoresis, the target protein in the gel was transferred onto a nitrocellulose membrane at $40 \mathrm{~V}$ for $0.5 \mathrm{~h}$, washed with eluant at least 3 times (10 $\mathrm{min} /$ time) and applied with the antibody. The protein was blocked with skim milk powder at $4^{\circ} \mathrm{C}$ overnight, incubated with the primary rabbit anti-rat antibody Nestin, GFAP, $\beta$-tubulin, MAP- $2, \beta$-acin polyclonal antibodies (diluted at 1:500; cat. nos. 19483-1-AP, 16825-1-AP, 10068-1-AP, 17490-1-AP, 20536-1-AP; Proteintech, Wuhan, China) at room temperature for $2 \mathrm{~h}$ and incubated with the secondary goat anti-rabbit polyclonal antibody (diluted at 1:1,000; cat. no. SA00001-2; Proteintech) at room temperature for $1 \mathrm{~h}$, and the ECL substrate was added (Sigma, St. Louis), followed by tabletting and imaging in the dark. The imaging results were quantified using ImageJ software (National Institutes of Health, Bethesda, MD, USA).

In vitro cell assay using the 96-well plate. A 96-well plate was selected and added with $1 \times 10^{5}$ neural stem cells/well, followed by culture for $24 \mathrm{~h}$. Three wells were only added with the normal medium as the control group $\left(\mathrm{C}_{0}\right), 3$ wells were added with the low-concentration sevoflurane $(0.2 \mathrm{~g} / \mathrm{ml})$ prepared by the medium as the low-concentration group $\left(\mathrm{C}_{1}\right), 3$ wells were added with the moderate-concentration of sevoflurane $(0.5 \mathrm{~g} / \mathrm{ml})$ as the moderate-concentration group $\left(\mathrm{C}_{2}\right)$, and 3 wells were added with the high-concentration sevoflurane $(1 \mathrm{~g} / \mathrm{ml})$ as the high-concentration group $\left(\mathrm{C}_{3}\right)$. After action for $12 \mathrm{~h}$, the medium was replaced with CCK- 8 and placed in the incubator with $\mathrm{CO}_{2}$ for $2 \mathrm{~h}$. The absorbance was measured at $480 \mathrm{~nm}$. Apoptosis rate $=\left(C_{0}-C_{x}\right) / C_{0}$. The experimental processes at 24 and $36 \mathrm{~h}$ were the same as that at $12 \mathrm{~h}$. 
A

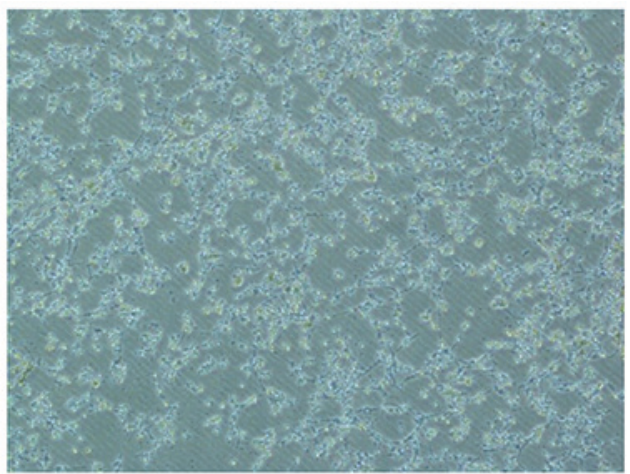

B

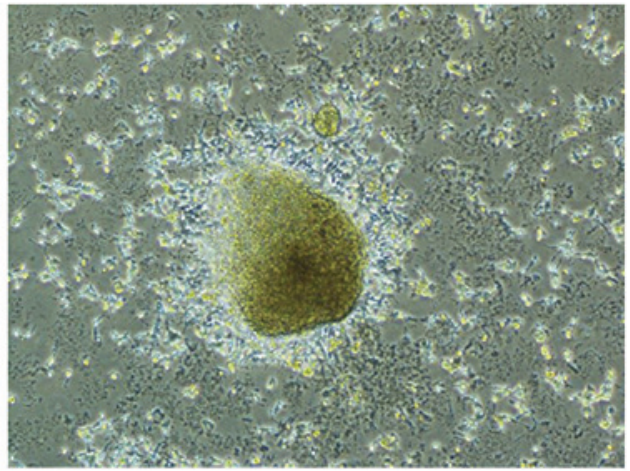

Figure 1. Isolation and culture of neural stem cells. (A) Neural stem cells distributed densely like stars. (B) A large number of cells gathered, forming a ball structure with a strong stereoscopic sense.

Detection of overall methylation content in cells via highperformance liquid chromatography (HPLC). The sample was added into the Hypersil BDS C18 column of a high-performance liquid chromatographic instrument (Shimadzu, Corp., Kyoto, Japan) using a microsyringe. Elution was performed with the mixed solution of methanol, sodium pentanesulfonate and triethylamine as the mobile phase at low temperature at a flow rate of $11 / \mathrm{min}$ (ultraviolet wavelength, $273 \mathrm{~nm}$; sensitivity, 0.01 AUPS). With deoxycytosine and methyldeoxycytosine standard samples as controls, the DNA methylation content in samples was detected. Each sample was detected 3 times, and the average was taken.

Statistical analysis. Statistical Product and Service Solutions (SPSS) 19.0 software (IBM Corp., Armonk, NY, USA) was used for processing of research data. Measurement data were expressed as (mean $\pm \mathrm{SD})$, and t-test and one-way analysis of variance (ANOVA) with Least Significant Difference post hoc test was used for the comparison of mean. Pearson's correlation analysis was used for correlation between methylation content and sevoflurane concentration. $\mathrm{P}<0.05$ indicated that the difference was statistically significant.

\section{Results}

Isolation and identification of neural stem cells. Primary neural stem cells had good transmittance and were distributed densely like stars in the visual field of an inverted microscope (Olympus, Tokyo, Japan) (Fig. 1A). At 5 days after culture, a large number of cells gathered, forming a ball structure with a strong stereoscopic sense, which was similar
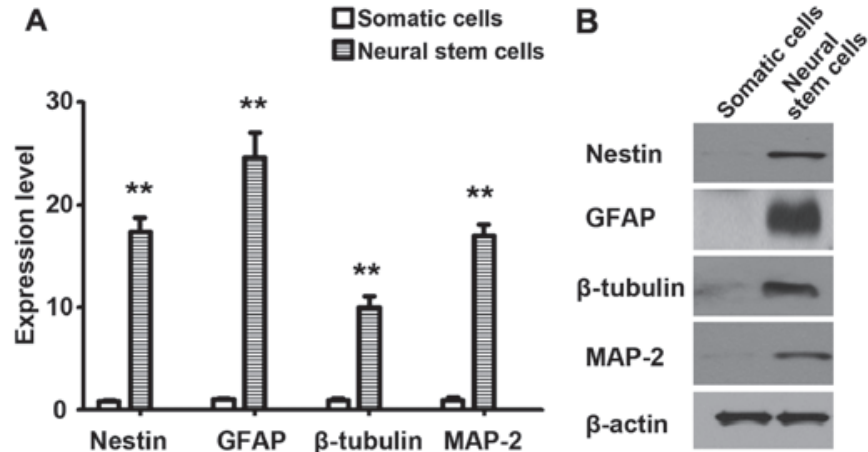

Figure 2. (A) RT-qPCR results. (B) Western blot analysis detection results. RT-qPCR, reverse transcription-quantitative polymerase chain reaction. ${ }^{* *} \mathrm{P}<0.01$, compared with somatic cells.

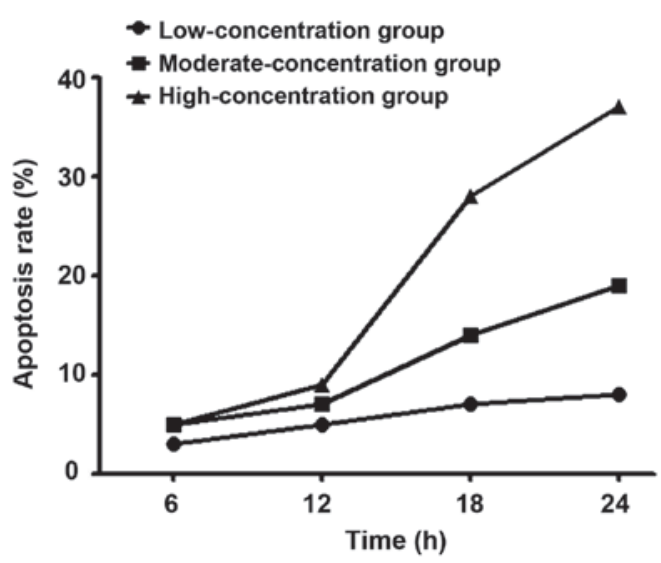

Figure 3. Effects of sevoflurane in different concentrations on apoptosis of neural stem cells detected via CCK-8 assay.

to a waxberry (Fig. 1B). At 3 days after induced differentiation, neural markers were detected via RT-qPCR and western blot analysis, and the results revealed that the expression levels of Nestin, GFAP, $\beta$-tubulin and MAP-2 were significantly higher than those in somatic cells $(\mathrm{P}<0.01)$ (Fig. 2).

Effects of sevoflurane in different concentrations on apoptosis of neural stem cells. Results of CCK-8 assay using the 96-well plate showed that with the increase of sevoflurane concentration, the apoptosis rate of stem cells was gradually increased, which was also progressively increased with the prolongation of time (Fig. 3).

The genomic DNA methylation content in the 4 groups of neural stem cells was detected via HPLC. The methylation content in the 3 groups of cells treated with sevoflurane was higher than that in the control group $(\mathrm{P}<0.05)$, and it was also higher in the high-concentration group than those in the moderate-concentration and low-concentration groups $(\mathrm{P}<0.05)$ (Fig. 4).

Correlation analysis between methylation content and sevoflurane concentration. According to the Pearson's correlation analysis, the methylation content in neural stem cells was closely correlated with the sevoflurane concentration, and the overall methylation content was increased with the increase of sevoflurane concentration (Fig. 5). 


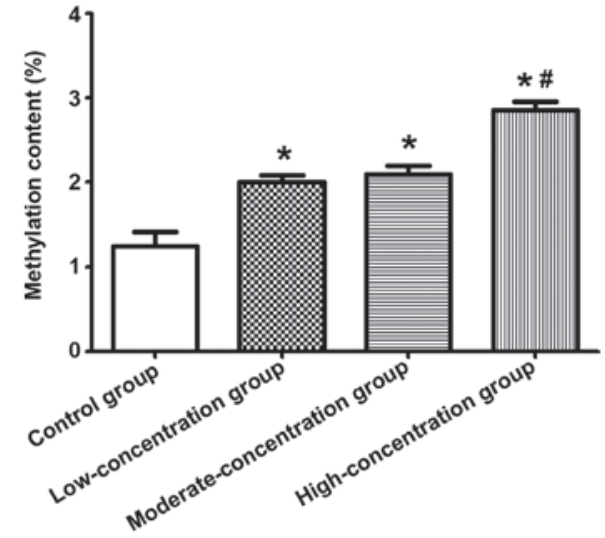

Figure 4. Comparison of genomic DNA methylation content in each group. ${ }^{*} \mathrm{P}<0.05$ vs. the control group, ${ }^{\#} \mathrm{P}<0.05$ vs. the low-concentration group.

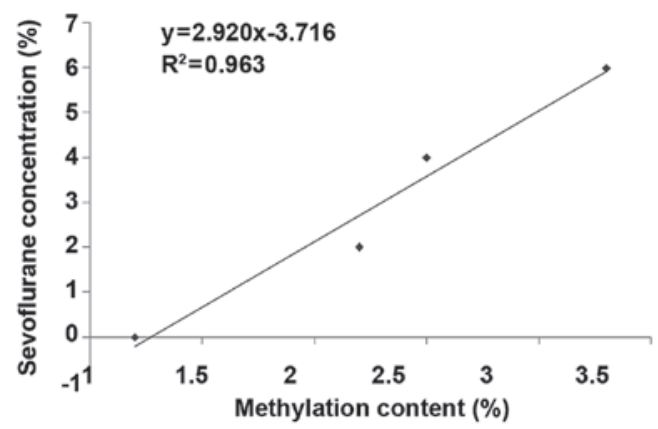

Figure 5. Correlation analysis between methylation content and sevoflurane concentration.

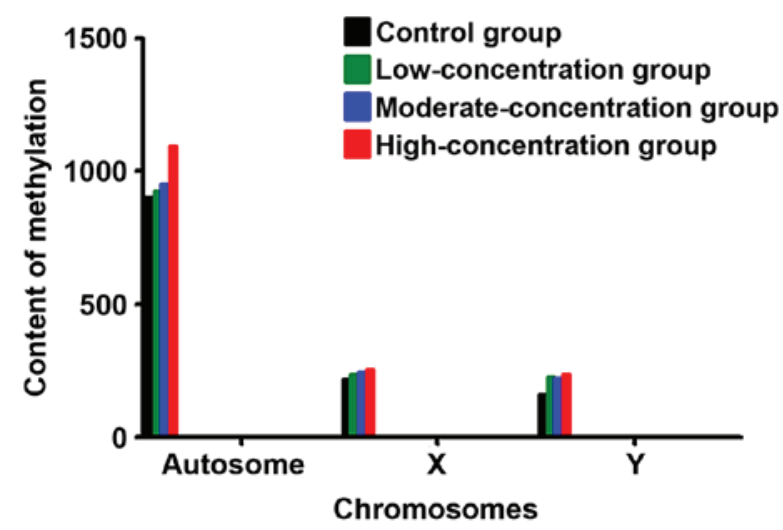

Figure 6. Comparison of distribution of methylation in the chromosome.

Comparison of distribution of methylation in the chromosome in each group. Methylation mostly occurred in the autosome, and the content of methylation in the high-concentration group was higher than that in the moderate-concentration, low-concentration and control groups $(\mathrm{P}<0.05)$. The degree of methylation on the sex chromosome had no significant differences among the four groups (Fig. 6).

\section{Discussion}

Neurodegenerative diseases lead to incurable pain for the patients worldwide. There is a lack of self-amplification and self-repairing capacity in nerve cells, so it difficult to make up for the loss of nerve cells once damaged (12). Moreover, nerverelated diseases gradually emerge with the decrease of neurons. Many neurologists worldwide have made unremitting efforts in the research on neurodegenerative diseases, and developed a variety of drugs and therapeutic methods successively, such as dopamine drugs, which, however, can mostly cure the symptom, instead of the underlying problem, and relieve symptoms in different degrees. Besides, the efficacy of drugs also gradually declines with the progression of the disease $(13,14)$. As a new therapeutic material, neural stem cells are highly valued currently, they possess self-repairing capacity and differentiate into neuronal cells or neuroglial cells required in the body, thus supplementing and repairing damaged nerve cells and enabling normal neuronal function $(15,16)$. Cornelissen et al (17) peeled off the hippocampal tissues of mice, hen screened, purified and cultured to obtain the ball-shaped nerve cells at 7 days, and added with inducer for neural induction. The immunofluorescence assay revealed that the neural markers are all highly expressed. In the present study, the hippocampus was also peeled off from rats and digested with trypsin to obtain primary neural stem cells. After culture for 5 days and induced differentiation for 3 days, the cellular morphology and surface markers met criteria for nerve cells, which were roughly consistent with the above study.

Great attention is required to the fact that the number of neural stem cells in the brain is small, and they can be easily damaged by external environment. One of the external environment factors with greater direct impact on the nerve is anesthetics that are often used in clinic and not easily detectable (18). Due to various advantages, sevoflurane is often used in the facial surgery for children. According to the study on clinical symptoms, sevoflurane has little effect on neural evaluation indexes. However, some clinical phenomena are obscured due to the strong metabolism of children. From a microscopic perspective, neural stem cells were cultured in vitro and fully treated with sevoflurane in different concentrations in the present study. It was found that the apoptosis rate of stem cells was increased with the increase of sevoflurane concentration and the prolongation of time, indicating that sevoflurane has a certain toxic effect on neural stem cells, and approximately $40 \%$ of cells are damaged after action under high concentration for $24 \mathrm{~h}$.

DNA methylation is a kind of DNA modification, and different degrees of methylation affect the structure and function of the whole gene. Therefore, methylation is an important index in the study on various clinical symptoms from the perspective of gene molecules $(19,20)$. Currently, there are many studies on methylation and tumorigenesis, and it was found that there is a certain correlation between them (21). There are few studies in the neurological field. In this study, results showed that the methylation content in cells treated with sevoflurane was higher than that in the control group, and it was also higher in the high-concentration group than that in the moderate-concentration and low-concentration groups. The methylation content in neural stem cells was closely correlated with the sevoflurane concentration, and the overall methylation content was increased with the increase of sevoflurane concentration. Methylation mostly occurred in the autosome, and the content of methylation in the high-concentration group was 
higher than that in the moderate-concentration, low-concentration and control groups. The degree of methylation on the sex chromosome had no significant difference among the four groups. The above results suggest that the higher the degree of methylation is, the higher the toxicity on neural stem cells may be from the perspective of molecular mechanism, so the degree of methylation can serve as an important index for the determination of neurotoxicity. However, the in vitro environment in the present study was different from the complex internal environment in the human body, so whether in vivo and in vitro results are consistent remains to be further verified.

In conclusion, the concentration of sevoflurane can affect the degree of methylation in neural stem cells of rats and produce certain cytotoxicity.

\section{Acknowledgements}

Not applicable.

\section{Funding}

The present study was supported by the Natural Science Foundation of Hainan Province (no. 20168314).

\section{Availability of data and materials}

The datasets used and/or analyzed during the current study are available from the corresponding author on reasonable request.

\section{Authors' contributions}

KW drafted the manuscript. KW and YT helped with the isolation and culture of neural stem cells. YZ and XL performed PCR and western blot analysis. XW, HH and SX contributed to CCK-8 assay and the high-performance liquid chromatography. All authors read and approved the final manuscript.

\section{Ethics approval and consent to participate}

The present study was approved by the Ethics Committee of Central South University Xiangya School of Medicine Affiliated Haikou Hospital (Haikou, China).

\section{Patient consent for publication}

Not applicable.

\section{Competing interests}

The authors declare that they have no competing interests.

\section{References}

1. Lie PPY and Nixon RA: Lysosome trafficking and signaling in health and neurodegenerative diseases. Neurobiol Dis 22: 94-105, 2019.

2. Gerhardt S and Mohajeri MH: Changes of colonic bacterial composition in Parkinson's disease and other neurodegenerative diseases. Nutrients 10: 708, 2018.

3. Maiti P and Dunbar GL: Use of curcumin, a natural polyphenol for targeting molecular pathways in treating age-related neurodegenerative diseases. Int J Mol Sci 19: E1637, 2018.
4. Kaneko N and Sawamoto K: Go with the flow: Cerebrospinal fluid flow regulates neural stem cell proliferation. Cell Stem Cell 22: 783-784, 2018.

5. Colle D, Farina M, Ceccatelli S and Raciti M: Paraquat and maneb exposure alters rat neural stem cell proliferation by inducing oxidative stress: New insights on pesticide-induced neurodevelopmental toxicity. Neurotox Res 34: 820-833, 2018.

6. Liu Q, Li Y, Zhou L, Li Y, Xu P, Liu X, Lv Q, Li J, Guo H, Cai H, et al: GRP78 promotes neural stem cell antiapoptosis and survival in response to oxygen-glucose deprivation (OGD)/reoxygenation

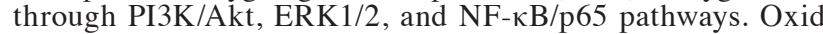
Med Cell Longev 3541807: 2018, 2018.

7. Petrella RA, Mollica PA,Zamponi M, Reid JA, Xiao S, Bruno RD and Sachs PC: 3D bioprinter applied picosecond pulsed electric fields for targeted manipulation of proliferation and lineage specific gene expression in neural stem cells. J Neural Eng 15: 056021,2018

8. Zhang G, Chen L, Chen W, Li B, Yu Y, Lin F, Guo X, Wang H, Wu G, Gu B, et al: Neural stem cells alleviate inflammation via neutralization of IFN- $\gamma$ negative effect in ischemic stroke model. J Biomed Nanotechnol 14: 1178-1188, 2018

9. Xu L, Shen J, Yu L, Sun J, McQuillan PM, Hu Z and Yan M: Role of autophagy in sevoflurane-induced neurotoxicity in neonatal rat hippocampal cells. Brain Res Bull 140: 291-298, 2018.

10. Iliescu DA, Ciubotaru A, Ghiţă MA, Dumitru A and Zăgrean L: Effect of sevoflurane preconditioning on light-induced retinal damage in diabetic rats. Rom J Ophthalmol 62: 24-33, 2018.

11. Livak KJ and Schmittgen TD: Analysis of relative gene expression data using real-time quantitative PCR and the 2(-Delta Delta $\mathrm{C}(\mathrm{T}))$ method. Methods 25: 402-408, 2001.

12. Salilew-Wondim D, Saeed-Zidane M, Hoelker M, Gebremedhn S, Poirier M, Pandey HO, Tholen E, Neuhoff C, Held E, Besenfelder U, et al: Genome-wide DNA methylation patterns of bovine blastocysts derived from in vivo embryos subjected to in vitro culture before, during or after embryonic genome activation. BMC Genomics 19: 424, 2018.

13. van der Heijden AG, Mengual L, Ingelmo-Torres M, Lozano JJ, van Rijt-van de Westerlo CCM, Baixauli M, Geavlete B, Moldoveanud C, Ene C, Dinney CP, et al: Urine cell-based DNA methylation classifier for monitoring bladder cancer. Clin Epigenetics 10: 71, 2018.

14. Jiao S, Liu Y, Yao Y and Teng J: miR-124 promotes proliferation and neural differentiation of neural stem cells through targeting DACT1 and activating Wnt/ $\beta$-catenin pathways. Mol Cell Biochem 449: 305-314, 2018.

15. Nguyen H, Kerimoglu C, Pirouz M, Pham L, Kiszka KA, Sokpor G, Sakib MS, Rosenbusch J, Teichmann U, Seong RH, et al: Epigenetic regulation by BAF complexes limits neural stem cell proliferation by suppressing Wnt signaling in late embryonic development. Stem Cell Rep 10: 1734-1750, 2018.

16. Petrik D, Myoga MH, Grade S, Gerkau NJ, Pusch M, Rose CR, Grothe B and Götz M: Epithelial sodium channel regulates adult neural stem cell proliferation in a flow-dependent manner. Cell Stem Cell 22: 865-878.e8, 2018.

17. Cornelissen L, Kim SE, Lee JM, Brown EN, Purdon PL and Berde CB: Electroencephalographic markers of brain development during sevoflurane anaesthesia in children up to 3 years old. Br J Anaesth 120: 1274-1286, 2018.

18. Murahata Y, Hikasa Y, Hayashi S, Shigematsu K, Akashi N, Osaki T, Tsuka T, Okamoto Y and Imagawa T: The effect of remifentanil on the minimum alveolar concentration (MAC) and MAC derivatives of sevoflurane in dogs. J Vet Med Sci 80: 1086-1093, 2018.

19. Feng C, Dong J, Chang W, Cui M and Xu T: The progress of methylation regulation in gene expression of cervical cancer. Int J Genomics 2018: 8260652, 2018.

20. Cheng J, Wei D, Ji Y, Chen L, Yang L, Li G, Wu L, Hou T, Xie L, Ding $\mathrm{G}$, et al: Integrative analysis of DNA methylation and gene expression reveals hepatocellular carcinoma-specific diagnostic biomarkers. Genome Med 10: 42, 2018.

21. Slieker RC, Relton CL, Gaunt TR, Slagboom PEand Heijmans BT: Age-related DNA methylation changes are tissue-specific with ELOVL2 promoter methylation as exception. Epigenetics Chromatin 11: 25, 2018.

This work is licensed under a Creative Commons Attribution-NonCommercial-NoDerivatives 4.0 International (CC BY-NC-ND 4.0) License. 